\title{
Optimization of single outsourcer-single subcontractor outsourcing relationship under reliability and maintenance constraints
}

\author{
Mohammed Haoues $^{1} \cdot$ Mohammed Dahane $^{2} \cdot$ Nadia Kinza Mouss $^{1}$
}

Received: 4 June 2018 / Accepted: 21 February 2019 / Published online: 4 March 2019

(c) The Author(s) 2019

\begin{abstract}
In this paper, we focus on outsourcing activities optimization problem in single period setting. In some situations, capacity planning or outsourcing is a one-time event and can be modeled as a single period problem. The aim of this research is to balance the trade-off between two echelons of a supply chain consisting of a single outsourcer and a single subcontractor. Each part is composed of a failure-prone single machine that produces one product type to satisfy market requirements. The outsourcer's manufacturing system is not able to satisfy the demand; in this case, outsourcing is allowed to recover the lack of capacity. We consider that the subcontractor can satisfy the demands of strategic clients and rent his machine for the outsourcer under a win-win partnership contract. We assume that the hazard failure rate depends on time and the adopted manufacture rate. When unforeseen failures occur, minimal repairs are implemented. Overhaul can be performed to reduce the degradation effects. Hence, we develop a mathematical model to define a profitability interval so that both parties of supply chain can be considered as winners. We seek to determine the contract parameters that suit both parties (duration, start and end dates, the production and outsourcing rates). Then, we develop an exact algorithm to solve the problem of single period optimization, which offers a better execution time through a series of test problems. Finally, we consider a sensitivity analysis based on outsourcing parameters (cost, periodicities, etc) to analyze their effects on partial costs and individual profit of each part, as well as the total profit generated by the system.
\end{abstract}

Keywords Outsourcing optimization $\cdot$ Production control $\cdot$ Reliability $\cdot$ Relationship outsourcer-subcontractor $\cdot$ Exhaustive search

\section{Introduction and literature review}

Supply chain management is the coordination and integration of supply chain activities, with the objective of achieving a viable competitive advantage. The supply chain management therefore includes a wide range of strategic, financial and operational issues (Geunes and Chang 2001).

Mohammed Haoues

m.haoues@univ-batna2.dz

Mohammed Dahane

mohammed.dahane@univ-lorraine.fr

Nadia Kinza Mouss

k.mouss@univ-batna2.dz

1 Laboratory of Automatic and Manufacturing, Industrial Engineering Department, Batna 2 University, 53, route de Constantine, Fésdis, Batna 05078, Algeria

2 Université de Lorraine, LGIPM, 57000 Metz, France
Industrial agreement is a strategic choice of companies, motivated by the search of benefits such as increasing skills, control and sharing of risks and the benefit of the value creation. Hence, it allows a collective and joint action that exceeds the individual limits. Various degrees of agreement between partners in a supply chain can be highlighted. We distinguish several partnership indicators such as cooperation, coordination, collaboration, communication and negotiation.

Therefore, cooperation is a collective action directed toward a common goal. In companies, this cooperation involves process in interaction. To carry a greater productivity, these interactions require a communication and negotiations between different actors. Thus, the disintegration of the common goal to a set of individual goals demands coordination and co-decisions. These co-decisions are negotiated to prevent or resolve conflicts that may occur between decisions and individual goals. The aim of this paper is to 
study the relationship outsourcer-subcontractor; we seek to increase the efficiency of supply chain through outsourcing activities optimization under reliability constraints.

In the literature, the subject of partnership is widely studied. For examples, we can cite: Thomas and Griffin (1996), Jayaraman and Pirkul (2001), Dudek and Stadtler (2005), Lehoux et al. (2010), Heydari and Norouzinasab (2015), Zabihi and Bafruei (2016) and Krapp and Kraus (2017). As mentioned above, the degree of partnership is measured by the cooperation, coordination, collaboration, communication and negotiation.

In our paper, the coordination is the synchronization of actions or outsourcing activities, in-house production and maintenance in time. It seeks to manage the consistency of individual actions of contractors and subcontractors, with respect to all activities of the system, and validate the individual objectives with respect to the common goal.

The collaboration means working together. The term of collaboration is used in time and place of cooperation when individual actions are not differentiable. So during production, the outsourcer appeals to the subcontractor for capacity reservation in order to overcome the shortage situations.

All phenomena concern the possibility, for a subject, to transmit information to another subject, with a language or code. Communication is an essential tool for the co-decision; negotiation, coordination and collaboration are done correctly between different actors in the supply chain.

However, the co-decision is a collaboration on decision making. In the case of a joint decision taken by a cluster of actors (outsourcers and subcontractors), we speak of codecision. This is defined as a decision-making collaboration.

Negotiation is defined as a mean of cooperation between different partners. It aims at finding an acceptable compromise between local objectives, sometimes diverging, which are from different decision centers.

There are many papers in the literature dealing with the cooperation and association in the supply chain. In their study, Thomas and Griffin (1996) have mentioned that the coordination in the supply chain improves its performances. Özen et al. (2009) and Ezimadu and Nwozo (2017) have proposed frameworks for supply chain management, with decision making under uncertainty and cooperation opportunities. In another work, Arshinder et al. (2011) have presented the literature review in order to highlight the importance of supply chain coordination. They discussed different mechanisms for coordination and managing uncertainty in supply chain coordination. The authors have presented various perspectives on supply chain coordination.

In a coordinated supply chain, many enterprises use outsourcing production operations or resources as one way of creating a win-win partnership among the members. Strategically, each enterprise focuses on its core business and seeks knowledge outside. This is in order to cope with diversification in market or retain central competition. These coordination mechanisms are vital to enhance the supply chain performance. Thus, coordinate can reduce lead times; minimize total costs and increase the organization flexibility (Lee and Sung 2008).

Almost all problems dealing with the issue of supply chain management are elaborated upon the costs reduction in different levels of supply chain. The total costs reduction reduces the price of products and so seeks to acquire additional market share and generates profits for future investments.

Productivity gains are sought all over in the supply chains in both transport and workshops, for example by limiting work in progress, the upstream and downstream inventory and the unproductive times of series change on equipments. Indeed, outsourcing reduces operating costs; in addition, it ensures lower investment conditions (Van Mieghem 1999).

Deavers (1997) identified the reasons why the enterprises have adopted outsourcing practices. Several researchers have proposed frameworks for effective and efficient outsourcing strategies. For example, Abdel-Malek et al. (2005) have discussed how to evaluate the performances of outsourcing policies in a multilayered supply chain. Aydinliyim and Vairaktarakis (2010) analyzed different problems of multiple-outsourcers sharing a single subcontractor, which takes into account the competition and the cooperation. Dolgui and Proth (2013) have provided a state-of-the-art analysis of global outsourcing in the late 2000s, and they presented a review of the advantages and disadvantages of outsourcing over the medium and long terms. The authors have not considered the outsourcing manner, but they showed the possible consequences of such decision.

Kim (2003) investigates a situation in which a manufacturing enterprise outsources its assemblage jobs to two contract manufacturers taking into account time and processing level simultaneously. Other authors have compared local and global optimization strategies in production planning. Tsai and Lai (2007) have developed a decision model for evaluating the comparative benefits of expanding the various kinds of capacity and outsourcing simultaneously. Saharidis et al. (2009) have formulated Markovian models for a coordinated decision making between two factories in a supply chain, which produces items to stock for meeting random demand. During stock out periods, each factory can purchase end items from subcontractors. Production and subcontracting decisions in each factory are made according to pull control policies.

When a company outsources its manufacturing resources, it is imperative to secure the availability and price of the requested capacity. The supply chain is frequently subjected to several risks and disturbances affecting its delivery reliability. For this reason, it is mandatory to consider different 
management practices (off-shoring, outsourcing, overtime, flow control, etc) in the supply chain to cope with disruptions and to obtain a reliable logistics network able to meet client requirements. Numerous of great enterprises, such as Ford, Hewlett-Packard, Cisco and Dell, have suffered from the lack of supply and instable prices (Nagali et al. 2008). To ensure the supply of capacity, outsourcers can establish agreements with their subcontractors to specify the price and quantity of capacity that they need.

Today, the maintenance of production units must be coherent with the production control policy. A rational use of resources can satisfy the demands with minimal costs. Maintenance policy can be also considered as an important process that needs forecasting models. In the literature, numerous researchers have studied the association between production control and maintenance management. Faghihinia and Mollaverdi (2012) have been interested to multicriterion decision-aided maintenance models. Analytical models for performance evaluation of the croissant automated production line with reparable machines have been developed in Tsarouhas (2015). Amelian et al. (2015) have studied the problem of optimal production and preventive maintenance rate in a failure-prone manufacturing system by using discrete event simulation. Cassady et al. (2001) have proposed a mathematical programming framework for selective maintenance of industrial systems. In (Tambe and Kulkarni 2014), a model integrating the selective maintenance, quality and production control has been developed. Khatab et al. (2014) have used the genetic algorithms for optimization of selective maintenance of multi-mission systems. In (Shahriari et al. 2016), authors have investigated the problem of just-in-time single machine with a cyclic preventive maintenance. In another work, Adeyeri and Mpofu (2017) have developed a system decision support tools for interactive trends monitoring and maintenance in a competitive environment.

Some authors have been interested on the problem of combined approach of production control and maintenance management, under subcontracting constraints. Dellagi et al. (2010) have considered a failure-prone production system, which is incapable to satisfy a constant demand. To fulfill this demand, the manufacturer uses the outsourcing practice. Two strategies have been developed; the first involves choosing one subcontractor among numerous. Authors have proved that the subcontractor's selection is conditioned by the unitary lost sales cost. However, the second consists in switching between two subcontractors. In (Dahane et al. 2011), authors have developed an integrated maintenance strategy, which combines the production under just-in-time and maintenance policy in a subcontracting conditions. The considered production system is composed of two machines, both of which produce a single-type product, and subject to breakdowns and can carry out outsourcing tasks. These works deal with the problem in continuous time. Contrary to these models, for discrete time models, Hajej et al. (2014) have considered subcontracting and product returns in the joint production and maintenance problem. The authors proposed resolution procedure based on linear quadratic stochastic optimization. A supply chain coordination issues with outsourcing options have been discussed in Haoues et al. (2012). In order to find the best outsourcing and maintenance periods, authors have compared between different strategies in a combined production and maintenance context.

Our proposed models are slightly different from the above studies. In their formulations, the authors have been interested in the development of integrated production and maintenance strategies under subcontracting constraints. In contrast, in the present paper, we study the outsourcing optimization under integrated production-maintenance approach.

Dahane and Rezg (2011) have formulated an outsourcing model for a single subcontractor multiple-outsourcers relationship; the objective of the proposed model is to analyze the viability and the profitability of outsourcing under a joint maintenance/production context. Haoues et al. (2011) have addressed the problem of outsourcing activities under integrated approach of production and maintenance. The authors have proposed global models for a simultaneous optimization of the profits for subcontractor-outsourcer relationship. Recently, in (Haoues et al. 2016), a combined policy to balance the trade-off between two echelon of supply chain has been proposed. This approach of in-house production/outsourcing, and maintenance, considers a noncyclical preventive maintenance, and the failure rate is depending on the production rates adopted in each period planning. Rivera-Gómez et al. (2016) have considered the effect of the variations of availability and degradation on the production capacity. If the facility is not capable to satisfy the demand, the outsourcing is adopted to improve the inhouse production. However, in-house resources in the contrary case satisfy the clients. Authors have developed a joint policy to control simultaneously the production and maintenance rates, and the frequency at which subcontractors are solicited. In another work, Rivera-Gómez et al. (2018) have analyzed the production, maintenance and subcontracting strategies in an integrated model. They considered that the degradation process involves effects on quality and reliability.

Almost all of the above cited approaches have considered principally the outsourcers or subcontractors viewpoint and optimized only the performances of one party. This does not certainly lead to an ideal solution for all memberships of a supply chain (Gheidar Kheljani et al. 2009). Even the two parts of relationship are considered, many works do not take into account the coordination between them. For example, in 
(Dahane et al. 2011), the subcontracting is studied according to two perspectives separately: the subcontractors' orientation and the outsourcers' orientation.

Different coordination models have been proposed to optimize the profits of all the members and alignment of decisions between entities of a supply chain. However, to the best of our knowledge, few studies have studied the problem of outsourcing optimization under reliability and maintenance constraints and consider the coordination between the parties of supply chain.

Our goal in this paper is to propose a mathematical formulation for the cooperation inter-companies. More precisely, we address the problem of simultaneous optimization of the profits of the subcontractor and the outsourcer, under a win-win partnership and reliability constraints. Although similar policies may be optimal individually to each part of the system, the sum of the profits realized individually can be much lower than the maximum benefit of the system that could generate under a coordinated policy (Saharidis et al. 2009). Thus, most of production planning models with outsourcing option only consider the amount of outsourcing in each production period, and do not consider the temporal aspect of the outsourcing, while our model decides the optimal timing of outsourcing. The time is an important key parameter in outsourcing contract. Therefore, for our approach, the cooperation can be studied according to two viewpoints: direct partnership or through an outsourcing platform. The cooperation in our paper is viewed as a collective decision-making action; the communication is an essential mean for synchronizing the actions spread out over different partners. We are in the context of co-decisions meant to individual actions coordination of each actor. This cooperation is based on the negotiation to prevent or resolve conflicts that may occur between decisions and individual goals.

This paper is structured as follows: In the second section, we present the problem description. "Mathematical models formulation" section is devoted to mathematical models of production plans. The "Resolution procedure" section is dedicated to detail the resolution procedure. Numerical example and sensitivity analysis are presented in "Numerical example and sensitivity analysis" section to illustrate the results. Finlay, conclusions and future directions research are provided in "Conclusions and future research directions" section.

\section{Problem description}

We consider two production units; each one consists of a single machine subject to random failures. The first for the subcontractor denoted $\left(u_{s}\right)$ which provides products to a direct customer (main customer), where its production capacity exceeds the principal demand. However, the second for the outsourcer is denoted $\left(u_{o}\right)$. This latter is related to outsourcing services, with the aim of improving its production capacity to meet constant customer demand. In this case, outsourcing is motivated by the incapacitated in-house production, knowing that its production system cannot meet the entire demand.

With the aim of increasing their productivity, reducing their costs, companies are adopting new strategies based on the call for subcontractors' companies, where production costs are lower. However, outsourcers companies are confronted with the following problems:

- The transportation problem of product induces a higher cost. The outsourcers companies, and according to comparative advantage, outsource the means of production instead of outsourcing products or tasks.

- The quality control problem of outsourced products. The outsourcers are unable to perform quality control of the product manufactured by the subcontractors. Therefore, the company can receive no-conforming products with desired product standards. Thus, can be rejected, which creates a shortfall. For this purpose, the outsourcers outsource the means of production in order to control production quality.

- The problem of maintenance activities management for all stakeholders. In fact, if the maintenance of subcontractor is not run by itself, the effectiveness of maintenance actions on the machines of subcontractor is not assured and the reliability of its unit is unknown. This induces uncontrollable downtime subcontractor for which there is loss of production.

According to problems imposed by the subcontractor, the outsourcer decides to produce at the maximum capacity and completes the rest of the demand by using outsourcing practice. Maintenance management for outsourcer can improve the reliability of its equipment. Unlike for subcontractor, maintenance activities management of its unit is not managed by the outsourcer, which cannot act to improve reliability. It is to note that the maintenance management of outsourcer company is managed independently of the subcontractor. Indeed, the maintenance strategies adopted by the outsourcer party depend only on the machine history. They do not take into account the state of the subcontractor that imposes downtime coinciding with the maintenance periods of the outsourcers unit.

\section{Notations}

Throughout the paper, the following notations are used: Index

$i \quad$ Index of a unit, with $i=s$, denotes the subcontractors' unit, and $i=o$ is the outsourcers' unit 
$j$ Index of a plan, with $j=\overline{\mathrm{wO}}$, denotes the plan without outsourcing, and $j=$ wo stands for the plan with outsourcing

\section{Decision variables}

$\pi_{\mathrm{ots}} \quad$ Outsourcing profit of the machine of subcontractor during one time unit

$c_{\text {ots }} \quad$ Outsourcing cost of the machine of subcontractor during one time unit

\begin{tabular}{|c|c|}
\hline$S_{1}^{i}, S_{2}^{i}$ & $\begin{array}{l}\text { Beginning and end instants of } \\
\text { outsourcing }\end{array}$ \\
\hline$f_{i}(\cdot)$ & $\begin{array}{l}\text { Probability density function associated } \\
\text { to the unit failure }\end{array}$ \\
\hline$F_{i}(\cdot)$ & $\begin{array}{l}\text { Probability distribution function associ- } \\
\text { ated to the unit failure }\end{array}$ \\
\hline$I(t)$ & Inventory level at the instant $t$ \\
\hline$\lambda^{i}(t)$ & Hazard failure rate function of the unit \\
\hline$\lambda_{n}^{i}(t)$ & $\begin{array}{l}\text { Nominal unit failure rate function when } \\
\text { unit } i \text { operates with the maximal produc- } \\
\text { tion capacity }\end{array}$ \\
\hline$M_{j}(T)$ & $\begin{array}{l}\text { Average number of failures during the } \\
\text { period } T\end{array}$ \\
\hline $\mathrm{IC}_{j}^{i}, \mathrm{MC}_{j}^{i}$ and $\mathrm{PC}_{j}^{i}$ & $\begin{array}{l}\text { Total costs of: inventory, maintenance } \\
\text { and production over the planning } \Delta t_{i} \\
\text { with or without outsourcing }\end{array}$ \\
\hline$\pi_{j}^{i}, \operatorname{Rev}_{j}^{i}$ & $\begin{array}{l}\text { Total profit and revenue over the plan- } \\
\text { ning } \Delta t_{i} \text { with or without outsourcing }\end{array}$ \\
\hline $\mathrm{SC}_{j}^{o}, d_{p_{j}}^{o}$ & $\begin{array}{l}\text { Total shortage cost and quantity over the } \\
\text { planning } \Delta P_{\mathrm{O}} \text { with or without } \\
\text { outsourcing }\end{array}$ \\
\hline $\operatorname{Rev}_{\text {OTS }}$ & $\begin{array}{l}\text { Total revenue of outsourcing over the } \\
\text { plan } \Delta P_{\mathrm{S}} \text {. }\end{array}$ \\
\hline $\mathrm{OC}^{\mathrm{O}}$ & $\begin{array}{l}\text { Total outsourcing cost of the unit } u_{\mathrm{s}} \text { over } \\
\text { the plan } \Delta t_{\mathrm{o}} \text {. }\end{array}$ \\
\hline$\pi^{i}$ & $\begin{array}{l}\text { Total profit realized by outsourcing inte- } \\
\text { gration over the plan } \Delta t_{i} \text {. }\end{array}$ \\
\hline
\end{tabular}

Parameters

$P_{1}^{i}, P_{2}^{i} \quad$ Beginning and end instants of the production plan period

$\Delta t_{i} \quad$ Total Production period duration of the unit $i$

$\Delta r_{i} \quad$ In-house production period duration of the unit $i$

$\Delta s_{i} \quad$ Outsourcing period duration, where $\Delta t_{\mathrm{o}}=\Delta t_{\mathrm{o}}+\Delta s_{\mathrm{o}}$ and $\Delta t_{\mathrm{s}}=\Delta r_{\mathrm{s}}+\Delta s_{\mathrm{s}}$.

$d_{i} \quad$ Direct demand addressed to production unit $u_{i}$

$c^{i}(T) \quad$ Production rate of $u_{i}$ during the period $T$

$c_{\max }^{i} \quad$ Maximal production capacity of $u_{i}$

$c_{\mathrm{h}}^{i} \quad$ Inventory holding cost of one product during one time unit for the unit $u_{i}$

$c_{\mathrm{p}}^{i} \quad$ Unitary production cost of the unit $u_{i}$

$p_{\mathrm{S}}^{i} \quad$ Unitary selling price of the unit $u_{i}$

$c_{\mathrm{r}}^{i}, c_{\mathrm{m}}^{i} \quad$ Unitary cost of minimal repair and preventive maintenance of the unit $u_{i}$

$c_{\mathrm{s}}^{\mathrm{o}} \quad$ Unitary shortage cost for the outsourcer

\section{Assumptions}

During this work, the following assumptions are considered:

1. The unmet demand is lost.

2. The products are imperishable with time.

3. Failures are detected instantaneously.

4. The owners perform machine maintenance. The law of machines degradation is Weibull type, the rate of failure increases with use.

5. The duration of minimal repairs and preventive maintenance actions is considered negligible.

6. Degradation of the machine of the subcontractor or the outsourcer party imposes random downtime. In addition, machines are subject to preventive maintenance policy, which aims to reduce the occurrence of failures. Downtime of machines due to maintenance shutdowns is assumed negligible (Assumption 4), and therefore do not cause a loss of demand.

7. Preventive maintenance actions are considered perfect. Each action restores the machine to "As Good As New" configuration.

8. During the production interval $\Delta t_{\mathrm{o}}, u_{\mathrm{o}}$ is used with a maximum production capacity $c_{\max }^{o}$.

9. During the production interval $\Delta t_{\mathrm{s}}$, the production unit $u_{\mathrm{s}}$ is operated with constant rates: $c^{\mathrm{s}}$ during $\Delta r_{1}^{\mathrm{s}}$ and $\Delta r_{2}^{\mathrm{s}}$ (where $c^{\mathrm{s}} \leq c_{\max }^{\mathrm{s}}$ ).

10. During the interval of outsourcing, $u_{\mathrm{s}}$ is used with a maximum production capacity $c_{\max }^{\mathrm{s}}$.

11. The production plan can start with a not-null level of stock: $\left(I\left(t_{1}^{i}\right) \geq 0\right)$

12. Outsourcing condition for outsourcer: The unit $u_{\mathrm{o}}$ cannot produce the amount requested during the interval $\Delta t_{\mathrm{o}}:\left(d_{\mathrm{o}}-I\left(t_{1}^{\mathrm{o}}\right)\right)>c_{\max }^{\mathrm{o}} \Delta t_{\mathrm{o}}$

13. Outsourcing condition for subcontractor: The unit $u_{\mathrm{s}}$ can satisfy all demand: $c^{\mathrm{s}} \cdot\left(\Delta r_{1}^{\mathrm{s}}+\Delta r_{2}^{\mathrm{s}}\right) \geq\left(d_{\mathrm{s}}-I\left(t_{1}^{\mathrm{s}}\right)\right)$.

14. The systems $u_{\mathrm{s}}$, and $u_{\mathrm{o}}$ with outsourcing $u_{\mathrm{s}}$ produce exactly the quantities requested.

We consider dependence between production and failure rates, such as the failure rate during each interval depends on the production rate. Therefore, operating at high rate accelerates the unit degradation and therefore increases the number and the total cost of repairs. For a given interval, the failure rate is written as follows: 
$\lambda_{i}(t)=\frac{c^{i}}{c_{\max }^{i}} \lambda_{n}^{i}(t)$

For each production facility, we conduct a preventive maintenance action at the end of each production period. However, two other preventive maintenance actions are performed on the machine $u_{\mathrm{s}}$ at the beginning and end of outsourcing period, which restores the production unit for the next production period.

\section{Mathematical models formulation}

Our goal is to determine simultaneously the optimal profits of the subcontractor and outsourcer during a finite planning horizon under a win-win partnership. The proposed analytical models are based on the gross revenues and generated costs.

First, we present the production planning models of subcontractor and outsourcer for the case without outsourcing option. Then, we present the case after outsourcing insertion.

\section{Production planning models without outsourcing option}

\section{- The subcontractor company}

Without outsourcing option, the production control policy of subcontractor consists of building a stock of finished products, with a production rate $c^{\mathrm{s}}$, to meet the direct demand $d_{\mathrm{s}}$ of its main customer. We have:

$c^{\mathrm{s}}=\frac{\left(d_{\mathrm{S}}-I\left(t_{1}^{\mathrm{s}}\right)\right)}{\Delta t_{\mathrm{s}}}$

The production unit produces exactly the quantity $d_{\mathrm{s}}-I\left(t_{1}^{\mathrm{s}}\right)$ (Assumption 14). The realized profit without outsourcing option is given by the following expression:

$\pi_{\overline{\mathrm{wo}}}^{\mathrm{s}}=\operatorname{Rev}_{\overline{\mathrm{wo}}}^{\mathrm{s}}-\left(\mathrm{IC}_{\overline{\mathrm{wo}}}^{\mathrm{s}}+\mathrm{MC}_{\overline{\mathrm{wo}}}^{\mathrm{s}}+\mathrm{PC}_{\overline{\mathrm{wo}}}^{\mathrm{s}}\right)$

where

Gross revenue is expressed by the following formula:

$\operatorname{Rev}_{\overline{\mathrm{wo}}}^{\mathrm{s}}=d_{\mathrm{s}} \cdot p_{\mathrm{s}}^{\mathrm{s}}$

Production cost is expressed by the following equation:

$\mathrm{PC}_{\overline{\mathrm{wo}}}^{\mathrm{s}}=\left(d_{\mathrm{s}}-I\left(t_{1}^{\mathrm{s}}\right)\right) \cdot c_{\mathrm{p}}^{\mathrm{s}}$

The inventory holding cost is given by Eq. 6:

$\mathrm{IC}_{\overline{\mathrm{wo}}}^{\mathrm{s}}=\left[I\left(t_{1}^{\mathrm{s}}\right) \cdot \Delta t_{\mathrm{s}}+\left(d_{\mathrm{s}}-I\left(t_{1}^{\mathrm{s}}\right)\right) \frac{\Delta t_{\mathrm{s}}}{2}\right] \cdot c_{\mathrm{h}}^{\mathrm{s}}$
Maintenance cost is calculated by the following expression:

$$
\begin{aligned}
\mathrm{MC}_{\overline{\mathrm{wo}}}^{\mathrm{s}} & =M_{\overline{\mathrm{wo}}}\left(\Delta t_{\mathrm{s}}\right) c_{\mathrm{r}}^{\mathrm{s}}+n \cdot c_{\mathrm{m}}^{\mathrm{s}} \\
& =\left[\frac{c^{\mathrm{s}}}{c_{\max }^{\mathrm{s}}} \int_{t_{1}^{s}}^{t_{2}^{\mathrm{s}}} \lambda_{\max }^{\mathrm{s}}(t) \mathrm{d} t\right] c_{\mathrm{r}}^{\mathrm{s}}+c_{\mathrm{m}}^{\mathrm{s}}
\end{aligned}
$$

\section{- The outsourcer company}

Production control policy of the outsourcer consists in operating the unit with maximum production capacity $c_{\max }^{\mathrm{o}}$, to minimize costs and shortage quantities to be outsourced (assumption 8). Without outsourcing option, the unit $u_{\mathrm{o}}$ operates with the maximum production capacity $c_{\max }^{\mathrm{o}}$ to meet the demand of customers $d_{\mathrm{o}}$. However, the in-house capacity of this unit cannot meet this demand. The profit without outsourcing option is given by the following expression:

$\pi_{\overline{\mathrm{wo}}}^{\mathrm{o}}=\mathrm{Rev}_{\overline{\mathrm{wo}}}^{\mathrm{o}}-\left(\mathrm{IC}_{\overline{\mathrm{wo}}}^{\mathrm{o}}+\mathrm{MC}_{\overline{\mathrm{wo}}}^{\mathrm{o}}+\mathrm{PC}_{\overline{\mathrm{wo}}}^{\mathrm{o}}+\mathrm{SC}_{\overline{\mathrm{wo}}}^{\mathrm{o}}\right)$

where

Gross revenue is expressed by the following formula:

$\operatorname{Rev}_{\overline{\mathrm{wo}}}^{\mathrm{o}}=c_{\text {max }}^{\mathrm{o}} \cdot \Delta t_{\mathrm{o}} \cdot p_{\mathrm{s}}^{\mathrm{o}}$

Production cost is calculated as follows:

$\mathrm{PC}_{\overline{\mathrm{wo}}}^{\mathrm{o}}=c_{\max }^{\mathrm{o}} \cdot \Delta t_{\mathrm{o}} \cdot c_{\mathrm{p}}^{\mathrm{o}}$

The expression of shortage cost, when this situation occurs, is given as follows:

$\mathrm{SC}_{\overline{\mathrm{wo}}}^{\mathrm{o}}=d_{p_{0}}^{\mathrm{o}} \cdot c_{\mathrm{s}}^{\mathrm{o}}=\left[\max \left[0,\left(d_{\mathrm{o}}-\left(I\left(t_{1}^{\mathrm{o}}\right)+c_{\max }^{\mathrm{o}} \cdot \Delta t_{\mathrm{o}}\right)\right)\right]\right] \cdot c_{\mathrm{s}}^{\mathrm{o}}$

The total inventory holding cost is written as follows:

$\mathrm{IC}_{\overline{\mathrm{wo}}}^{\mathrm{o}}=\Delta t_{\mathrm{o}} \cdot\left[I\left(t_{1}^{\mathrm{o}}\right)+\frac{c_{\max }^{\mathrm{o}} \cdot \Delta t_{\mathrm{o}}}{2}\right] \cdot c_{\mathrm{h}}^{\mathrm{o}}$

Finally, formula 13 gives the maintenance cost over the planning period:

$\mathrm{MC}_{\overline{\mathrm{wo}}}^{\mathrm{o}}=M_{\mathrm{o}}\left(\Delta t_{\mathrm{o}}\right) \cdot c_{\mathrm{r}}^{\mathrm{o}}+c_{\mathrm{m}}^{\mathrm{o}}$

such as: $M_{\mathrm{o}}\left(\Delta t_{\mathrm{o}}\right)=\int_{t_{1}^{o}}^{t_{2}^{o}} \lambda_{\max }^{\mathrm{o}}(t) \mathrm{d} t$

Production planning models after outsourcing insertion option

- The subcontractor 
The insertion of the outsourcing task requires a new optimization of production plan based on new production rates. Consider first $c^{\mathrm{s}}$, production rate during production periods $\Delta r_{1}^{\mathrm{s}}$ and $\Delta r_{2}^{\mathrm{s}} . c_{\max }^{\mathrm{s}}$ means the production rate adopted by the subcontractor during the outsourcing period. The expression of the subcontractor profit is based on the revenue earned from the production and outsourcing, and resulting costs of storage, maintenance and production. It is expressed as follows:

$\pi_{\mathrm{wo}}^{\mathrm{s}}=\operatorname{Rev}_{\mathrm{wo}}^{\mathrm{s}}+\pi_{\mathrm{OTS}}-\left(\mathrm{IC}_{\mathrm{wo}}^{\mathrm{s}}+\mathrm{MC}_{\mathrm{wo}}^{\mathrm{s}}+\mathrm{PC}_{\mathrm{wo}}^{\mathrm{s}}\right)$

where

Gross revenue is expressed by the following formula:

$\operatorname{Rev}_{\mathrm{wo}}^{\mathrm{s}}=d_{\mathrm{s}} \cdot p_{\mathrm{s}}^{\mathrm{s}}$

Production cost is expressed by the following equation:

$\mathrm{PC}_{\mathrm{wo}}^{\mathrm{s}}=\left(d_{\mathrm{s}}-I\left(t_{1}^{\mathrm{s}}\right)\right) \cdot c_{\mathrm{p}}^{\mathrm{s}}$

The profit realized from the outsourcing is calculated as follows:

$\pi_{\mathrm{OTS}}=\Delta s_{\mathrm{s}} \cdot \pi_{\mathrm{ots}}$

The inventory cost is expressed by Eq. 18:

$\mathrm{IC}_{\mathrm{wo}}^{\mathrm{s}}=\left[c^{\mathrm{s}} \cdot \Delta r_{1}^{\mathrm{r}} \cdot\left(\frac{\Delta r_{1}^{\mathrm{s}}}{2}+\Delta s_{\mathrm{s}}+\Delta r_{2}^{\mathrm{s}}\right)+I\left(t_{1}^{\mathrm{s}}\right) \cdot \Delta t_{\mathrm{s}}+\frac{c^{\mathrm{s}} \cdot\left(\Delta r_{2}^{\mathrm{s}}\right)^{2}}{2}\right] \cdot c_{\mathrm{h}}^{\mathrm{s}}$

Maintenance cost is calculated by the following expression:

$\mathrm{MC}_{\mathrm{wo}}^{\mathrm{s}}=M_{\mathrm{wo}}\left(\Delta t_{\mathrm{s}}\right) c_{\mathrm{r}}^{\mathrm{s}}+3 c_{\mathrm{m}}^{\mathrm{s}}$
such as: $M_{\mathrm{wo}}\left(\Delta t_{\mathrm{s}}\right)=\left[\frac{c^{\mathrm{s}}}{c_{\max }^{\mathrm{s}}}\left(\int_{t_{1}^{\mathrm{s}}}^{s_{1}^{\mathrm{s}}} \lambda_{\max }^{\mathrm{s}}(t) \mathrm{d} t+\int_{s_{2}^{\mathrm{s}}}^{t_{2}^{\mathrm{s}}} \lambda_{\max }^{\mathrm{s}}(t) \mathrm{d} t\right)\right.$
$\left.+\int_{s_{1}^{\mathrm{s}}}^{s_{2}^{\mathrm{s}}} \lambda_{\max }^{\mathrm{s}}(t) \mathrm{d} t\right]$

- The outsourcer

The outsourcing option consists in renting the machine of the subcontractors unit $u_{\mathrm{s}}$ to enhance their production capacity. In order to minimize the outsourcing amount, the unit $u_{\mathrm{o}}$ (in-house production) works with its maximum production capacity $c_{\max }^{0}$ (assumption 8 ). The missing production capacity is outsourced by renting $u_{\mathrm{s}}$. The total production capacity is sufficient to meet the demand $d_{\mathrm{o}}$ (assumption 14). The expression of outsourcer profit is based on the revenue earned from the production and storage costs, maintenance, production, shortages and outsourcing:

$\pi_{\mathrm{wo}}^{\mathrm{o}}=\mathrm{Rev}_{\mathrm{wo}}^{\mathrm{o}}-\left(\mathrm{IC}_{\mathrm{wo}}^{\mathrm{o}}+\mathrm{MC}_{\mathrm{wo}}^{\mathrm{o}}+\mathrm{PC}_{\mathrm{wo}}^{\mathrm{o}}+\mathrm{SC}_{\mathrm{wo}}^{\mathrm{o}}+\mathrm{OC}^{\mathrm{o}}\right)$

where

Gross revenue is expressed by the following formula:

$\operatorname{Rev}_{\mathrm{wo}}^{\mathrm{o}}=\left(c_{\text {max }}^{\mathrm{o}} \cdot \Delta t_{\mathrm{o}}+c_{\text {max }}^{s} \cdot \Delta s_{\mathrm{s}}\right) \cdot p_{\mathrm{s}}^{\mathrm{o}}$

Production cost is calculated as follows:

$\mathrm{PC}_{\mathrm{wo}}^{\mathrm{o}}=c_{\text {max }}^{\mathrm{o}} \cdot \Delta t_{\mathrm{o}} \cdot c_{\mathrm{p}}^{\mathrm{o}}$

Outsourcing cost is expressed by formula 23 :

$\mathrm{OC}^{\mathrm{o}}=\Delta s_{\mathrm{s}} \cdot c_{\mathrm{ots}}$

The expression of shortage cost, when this situation occurs, is given as follows:

$S C_{\overline{\mathrm{wo}}}^{\mathrm{o}}=d_{p_{0}}^{\mathrm{o}} \cdot c_{\mathrm{s}}^{\mathrm{o}}=\left[\max \left[0,\left(d_{\mathrm{o}}-\left(I\left(t_{1}^{o}\right)+c_{\text {max }}^{o} \cdot \Delta t_{\mathrm{o}}\right)\right)\right]\right] \cdot c_{\mathrm{s}}^{\mathrm{o}}$

The total inventory holding cost is written as follows:

$\mathrm{IC}_{\mathrm{wo}}^{\mathrm{o}}=\left[\begin{array}{c}c_{\max }^{\mathrm{o}} \cdot \Delta r_{1}^{\mathrm{o}} \cdot\left(\frac{\Delta r_{1}^{\mathrm{o}}}{2}+\Delta s_{\mathrm{o}}+\Delta r_{2}^{\mathrm{o}}\right)+I\left(t_{1}^{\mathrm{o}}\right) \cdot \Delta t_{\mathrm{o}} \\ +\frac{c_{\max }^{\mathrm{o}}\left(\Delta r_{2}^{\mathrm{o}}\right)^{2}}{2}+\Delta s_{\mathrm{o}} \cdot\left(c_{\max }^{\mathrm{o}}+c_{\max }^{\mathrm{s}}\right) \cdot\left(\frac{\Delta s_{\mathrm{o}}}{2}+\Delta r_{2}^{\mathrm{o}}\right)\end{array}\right] \cdot c_{\mathrm{h}}^{\mathrm{o}}$

Finally, formula 26 gives the maintenance cost over the planning period:

$\mathrm{MC}_{\mathrm{wo}}^{\mathrm{o}}=M_{\mathrm{o}}\left(\Delta t_{\mathrm{o}}\right) \cdot c_{\mathrm{r}}^{\mathrm{o}}+c_{\mathrm{m}}^{\mathrm{o}}$

such as: $M_{\mathrm{o}}\left(\Delta t_{\mathrm{o}}\right)=\int_{t_{1}^{\mathrm{o}}}^{t_{2}^{\mathrm{o}}} \lambda_{\max }^{\mathrm{o}}(t) \mathrm{d} t$

\section{Resolution procedure}

We use an exhaustive search to solve effectively these models. All tests of this paper have been performed on a desktop computer, Pentium 4 with Intel Core 2 Duo CPU ( $3 \mathrm{GHz}$ 2.93), and 2 GB RAM. We use MATLAB to implement different algorithms. In the following, we give different algorithms of our analytical resolution procedure. 


\section{Algorithme.1 (Separate Optimization Algorithm - SOA -)}

\section{Initialization}

Initialize various parameters and variables;

Calculate different costs, revenues and profits of the outsourcer and the subcontractor without outsourcing option;

\section{Main program}

ProfitDoMax $=-\infty$;

For $s_{1}^{o}=t_{1}^{o}$ to $t_{2}^{o}-1$

For $s_{2}^{o}=s_{1}^{o}+1$ to $t_{2}^{o}$

Calculate different costs, revenue and profit of outsourcer with

outsourcing option;

If ProfitDo > ProfitDOMax then

End if

Save the best results;

\section{End For}

\section{End For}

ProfitsTMax $=-\infty$;

For $s_{1}^{S}=t_{1}^{S}$ to $t_{2}^{S}-1$

For $s_{2}^{s}=s_{1}^{s}+1$ to $\min \left(\Delta t_{s}-\left(\frac{d_{s}-I\left(t_{1}^{s}\right)}{c_{\max }^{s}}\right)+s_{1}^{s}, t_{2}^{s}\right)$

Calculate different costs, revenue and profit of subcontractor with outsourcing option;

If ProfitST > ProfitSTMax

End if

Save the best results;

End For

End For

\section{Algorithme.2 (Combined Optimization Algorithm - COA -)}

\section{Initialization}

Initialize various parameters and variables;

Calculate different costs, revenues and profits of the outsourcer and the subcontractor without outsourcing option;

\section{Main program}

ProfitDoMax $=-\infty$;

ProfitsTMax $=-\infty$;

ProfitTotalMax $=-\infty$;

For $s_{1}^{S}=t_{1}^{S}$ to $t_{2}^{S}-1$

For $s_{2}^{s}=s_{1}^{s}+1$ to $\min \left(\Delta t_{s}-\left(\frac{d_{s}-I\left(t_{1}^{s}\right)}{c_{\text {max }}^{s}}\right)+s_{1}^{s}, t_{2}^{s}\right)$

For $s_{1}^{o}=t_{1}^{o}$ to $t_{2}^{o}-1$

For $s_{2}^{o}=s_{1}^{o}+1$ to $t_{2}^{o}$

If $s_{1}^{S}=s_{1}^{o} \& s_{2}^{S}=s_{2}^{o}$

Compute different costs, revenues and profits of

outsourcer and subcontractor with outsourcing option;

If ProfitTotal > ProfitTotalMax

\section{End If}

Save the best results;

End If

End For

\section{End For}

End For

End For 


\section{Numerical example and sensitivity analysis}

In this section, we provide a numerical example to illustrate our results. Let us consider two production units, one for the subcontractor and one for the outsourcer. Specific data for each unit are given as follows:

For the subcontractor: consider the example of (Dahane and Rezg 2011):

$d_{\mathrm{s}}=32$ units; $\Delta t_{\mathrm{s}}=30$ time units; $c_{\max }^{\mathrm{s}}=2$ units/time units; $I\left(t_{1}^{\mathrm{s}}\right)=2$ units.

For the outsourcer: $d_{\mathrm{o}}=65$ units; $\Delta t_{\mathrm{o}}=25$ time units; $c_{\text {max }}^{\mathrm{o}}=2$ units/time units; $I\left(t_{1}^{\mathrm{o}}\right)=5$ units.

We consider that the failure rate function, when the production units operate with maximal capacities $c_{\max }^{i}$ follows a Weibull distribution with two parameters $\alpha=2$ and $\beta=100$. Thus, the function is written as follows:

$\lambda_{n}(t)=(2 / 100) \cdot(t / 100)$

The rest of parameters are summarized in Table 1 .

For these parameters, the optimal results of the case without outsourcing integration are summarized in Table 2.

Without outsourcing, the profit of the subcontractor is equal to 249.255 m.u. The production unit meets the entire demand, it satisfies demand, but production capacity is not used optimally. For the outsourcer, the profit is 105.5 m.u, but a shortage situation occurs, and generates a shortage cost equal to 220 m.u. Thus, the total profit realized by both parties of system without the partnership is equal to 354.755 m.u.
The optimal results of separate optimization are summarized in Table 3.

Figure 1a and $\mathrm{b}$ shows the profits realized for the subcontractor and the outsourcer with outsourcing in separate optimization, compared with the profit realized without outsourcing.

The integration of outsourcing involves a new system optimization. If we treat each part separately (i.e., separate optimization), the subcontractor realizes a total profit equals to $392.095 \mathrm{~m}$.u, it is obtained for $s_{1}^{\mathrm{s}}=0$ and $s_{2}^{\mathrm{s}}=5$; the profit from the integration of outsourcing is $142.84 \mathrm{~m}$.u. (which expresses $36.43 \%$ of the total profit of subcontractor); while the profit realized by the outsourcer is $265.5 \mathrm{~m}$.u; it is obtained for $s_{1}^{\mathrm{o}}=20$ and $s_{2}^{\mathrm{o}}=25$. The profit from the integration of outsourcing is $160 \mathrm{~m}$.u. (which expresses $60.26 \%$ of the total profit of outsourcer). In this case, the win-win partnership is impossible because each company wants to maximize profits regardless of the other party.

However, the total profit of both parties realized by the simultaneous optimization under a win-win partnership is 809.467 m.u. obtained for $s_{1}^{\mathrm{o}}=s_{1}^{\mathrm{s}}=20$ and $s_{2}^{\mathrm{o}}=s_{2}^{\mathrm{s}}=25$. The profit from the integration of outsourcing in the entire system is 279.712 m.u. or $34.55 \%$ of the total profit of the system. If we analyze each part separately, we can see that the subcontractor realized a profit increase of $54.18 \%$ compared to the case without inclusion of outsourcing. For the outsourcer, an increase of $39.74 \%$ was achieved. The optimal
Table 1 Set of systems' parameters

\begin{tabular}{|c|c|c|c|c|c|c|c|c|}
\hline \multirow{2}{*}{$\begin{array}{l}\text { Parameters } \\
\text { Production unit }\end{array}$} & \multicolumn{6}{|c|}{ Unitary costs (monetary units) } & \multicolumn{2}{|c|}{$\begin{array}{l}\text { Profit and } \\
\text { selling price }\end{array}$} \\
\hline & $c_{\mathrm{h}}$ & $c_{\mathrm{p}}$ & $c_{r}$ & $c_{\mathrm{m}}$ & $c_{\mathrm{s}}$ & $c_{\mathrm{ots}}$ & $p_{\mathrm{s}}$ & $\pi_{\mathrm{ots}}$ \\
\hline Subcontractor & 0.19 & 1.5 & 41 & 23 & - & - & 13 & 35 \\
\hline Outsourcer & 0.2 & 2 & 40 & 22 & 22 & 35 & 12 & - \\
\hline
\end{tabular}

Table 2 Generated costs, realized profits without outsourcing option

\begin{tabular}{lllllll}
\hline Parameters & \multicolumn{3}{l}{ Total costs (m.u) } & & Total profits & $\begin{array}{l}\text { Outsourcing } \\
\text { profits (m.u) }\end{array}$ \\
\cline { 2 - 5 } Production unit & IC & MC & PC & SC & $\pi$ & - \\
\hline Subcontractor & 96.9 & 24.845 & 45 & - & 249.255 & - \\
Outsourcer & 150 & 24.5 & 100 & 220 & 105.5 & - \\
\hline
\end{tabular}

Table 3 Generated costs, realized profits with outsourcing option-separate optimization

\begin{tabular}{|c|c|c|c|c|c|c|}
\hline \multirow{2}{*}{$\begin{array}{l}\text { Parameters } \\
\text { Production unit }\end{array}$} & \multicolumn{4}{|c|}{ Total costs (m.u) } & \multirow{2}{*}{$\begin{array}{l}\text { Total profits } \\
\pi\end{array}$} & \multirow{2}{*}{$\begin{array}{l}\text { Outsourcing } \\
\text { profits (m.u) }\end{array}$} \\
\hline & IC & $\mathrm{MC}$ & $\mathrm{PC}$ & STC & & \\
\hline Subcontractor & 82.65 & 71.255 & 45 & - & 392.095 & 142.84 \\
\hline Outsourcer & 155 & 24.5 & 100 & 175 & 265.5 & 160 \\
\hline
\end{tabular}


The generated profit during the production planning

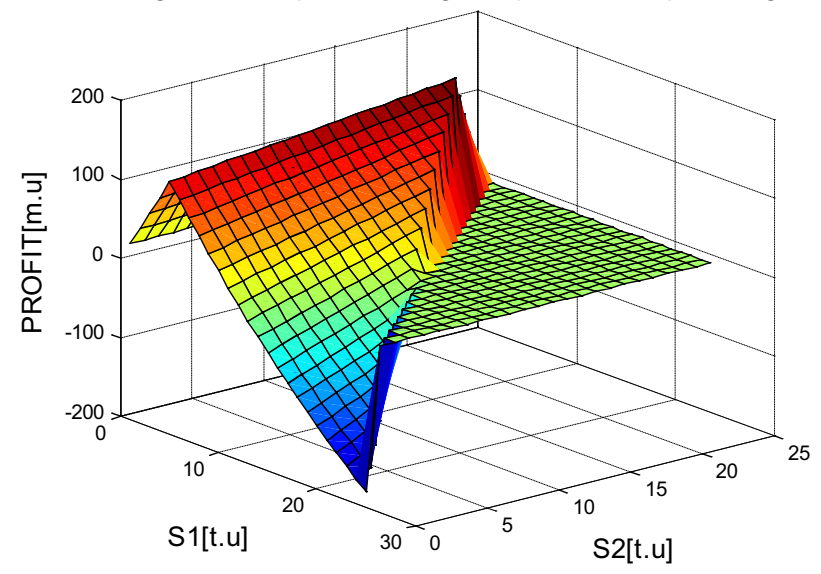

(a)
The generated profit during the production planning

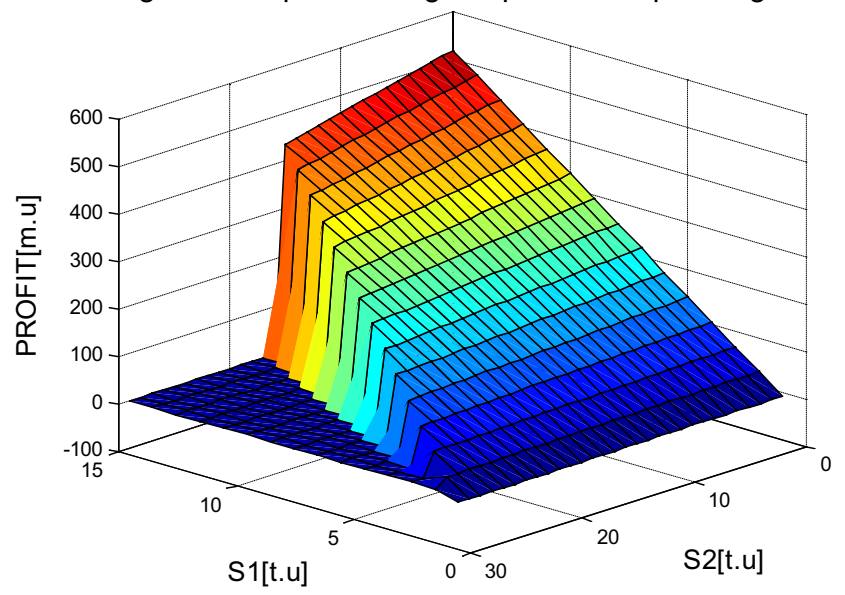

(b)

Fig. 1 Realized profits with outsourcing option—separate optimization

Table 4 Generated costs, realized profits with outsourcing option-integrated optimization

\begin{tabular}{|c|c|c|c|c|c|c|c|c|}
\hline \multirow{2}{*}{$\begin{array}{l}\text { Parameters } \\
\text { Production unit }\end{array}$} & \multicolumn{5}{|c|}{ Total costs (m.u) } & \multicolumn{2}{|c|}{ Total profits } & \multirow{2}{*}{$\begin{array}{l}\text { Outsourcing } \\
\text { profits (m.u) }\end{array}$} \\
\hline & IC & $\mathrm{MC}$ & $\mathrm{PC}$ & $\mathrm{SC}$ & $C_{\mathrm{OTS}}$ & $\pi$ & $\pi_{\text {OTS }}$ & \\
\hline Subcontractor & 105.45 & 71.583 & 45 & - & - & 368.967 & 175 & 119.712 \\
\hline Outsourcer & 155 & 24.5 & 100 & 0 & 175 & 265.5 & - & 160 \\
\hline
\end{tabular}

The generated profit during the production planning

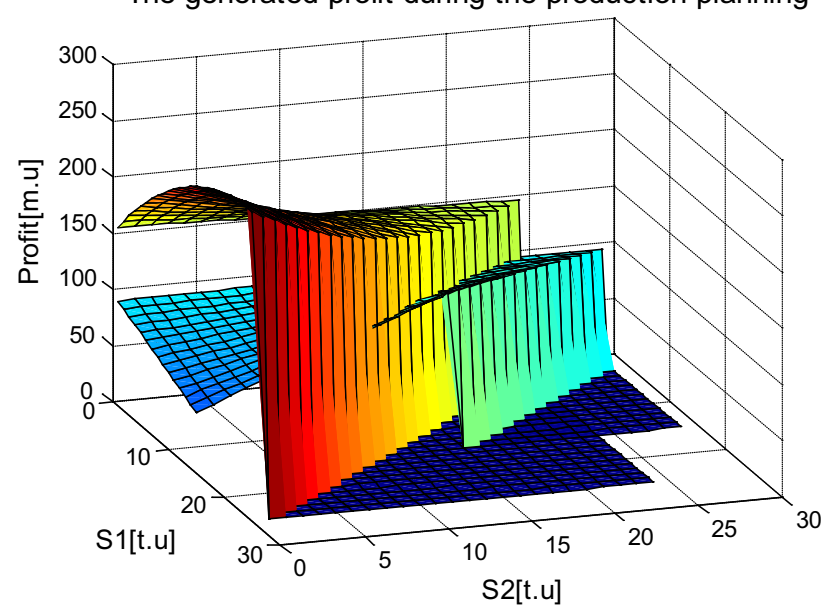

Fig. 2 Equilibrium interval of the profit between subcontractor and outsourcer under win-win partnership

results of simultaneous optimization are summarized in Table 4.

Figure 2 shows the trade-off interval profits (feasibility and profitability intervals) between the subcontractor and the outsourcer under integrated optimization, compared with separate optimization.

We perform a sensitivity analysis based on outsourcing parameters (costs, periods, etc) to find their effects on individual profit realized by the subcontractor, and the total profit realized by the outsourcer.

\section{Sensitivity analysis based on outsourcing periodicities}

Table 5 presents and summarizes the results of experiments dealing with the change in profit of the subcontractor, the outsourcer, as well as the complete system according to the period of outsourcing. From this table and Fig. 3, we observe that the variation in the period of outsourcing has an effect on the cost of storage of both parties, on the maintenance costs of the subcontractor; and consequently on the profits realized by the subcontractor, respectively, the outsourcer.

However, the change in the outsourcing period has no effect on outsourcing integration profit, and the production costs of the two parts, the outsourcing profit and the outsourcing cost, respectively, for the subcontractor and the outsourcer, and finally the maintenance cost of the outsourcer. 
Journal of Industrial Engineering International (2019) 15:395-409

405

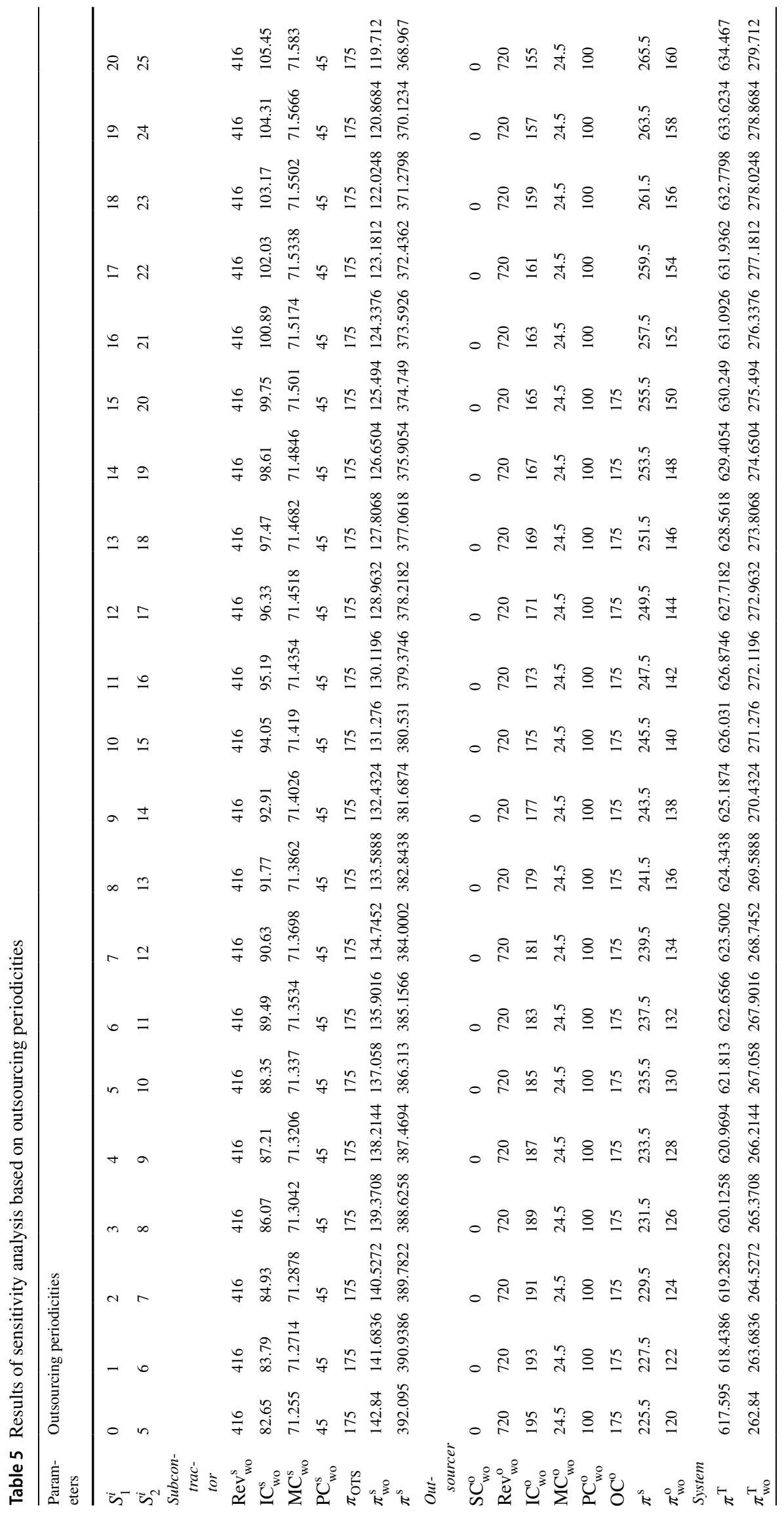

Springer 


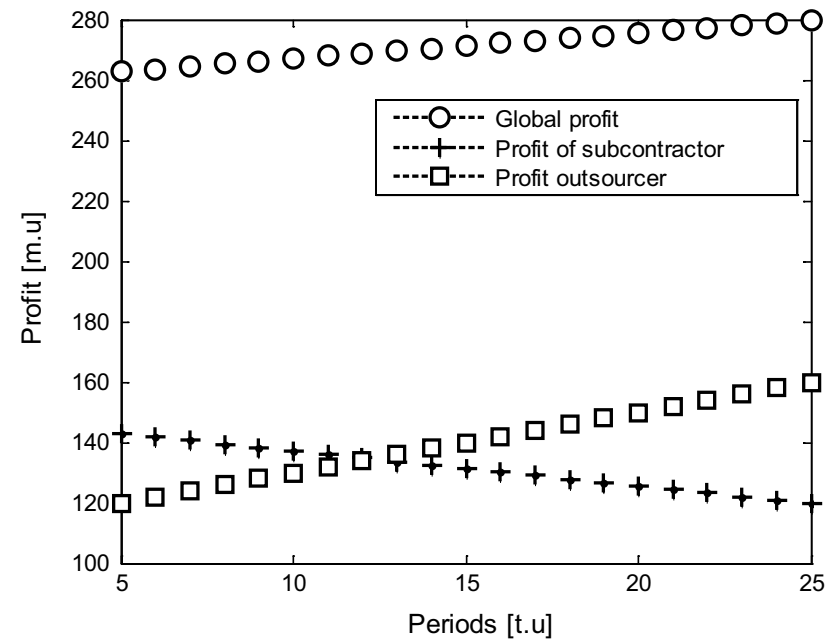

Fig. 3 Variation of the subcontractor, the outsourcer and the whole system profits according to outsourcing periodicities

\section{Sensitivity analysis based on outsourcing costs}

Table 6 summarizes the results of experiments dealing with the change in profit of the subcontractor, the outsourcer, as well as the complete system based on unitary outsourcing prices. From this table and Fig. 4, we find that the change in the outsourcing price has an effect on the profit and cost of outsourcing; and consequently on the profits realized by the subcontractor and the outsourcer, respectively. They are inversely proportional, so it has no effect on the total profit of the complete system. The same reasoning for the gain generated from the integration of outsourced activities. For the rest of the variables, we note that these settings are not changed during the experiments.

\section{Conclusions and future research directions}

In this paper, we have studied the optimization problem of the integration of outsourced activities for single-production period. The studied system is composed of two manufacturing systems; each system consists of one randomly failing and repairable machine, which produces a single product. The goal is to develop an effective and efficient partnership through outsourcing contracts among the supply chain members.

We have developed a global mathematical model to find the trade-off between single outsourcer and single subcontractor. We have focused on the determination of the optimal plans maximizing the total profits for two parts, which take into account the reliability constraints reflecting the dependence between production and failure rates.

Exhaustive search algorithms have been implemented to define a profitability interval for both parties to achieve a win-win policy. The different contract parameters that suit both parties have been determined (duration, start and end dates, the production and outsourcing rates). To demonstrate the robustness of our models, we have performed a sensitivity analysis based on outsourcing parameters (costs, periodicities, etc) to investigate their effects on partial costs and individual profit of each part, as well as the total profit realized by the system. The combined approach has revealed a higher profit increase as compared to the separate planning 


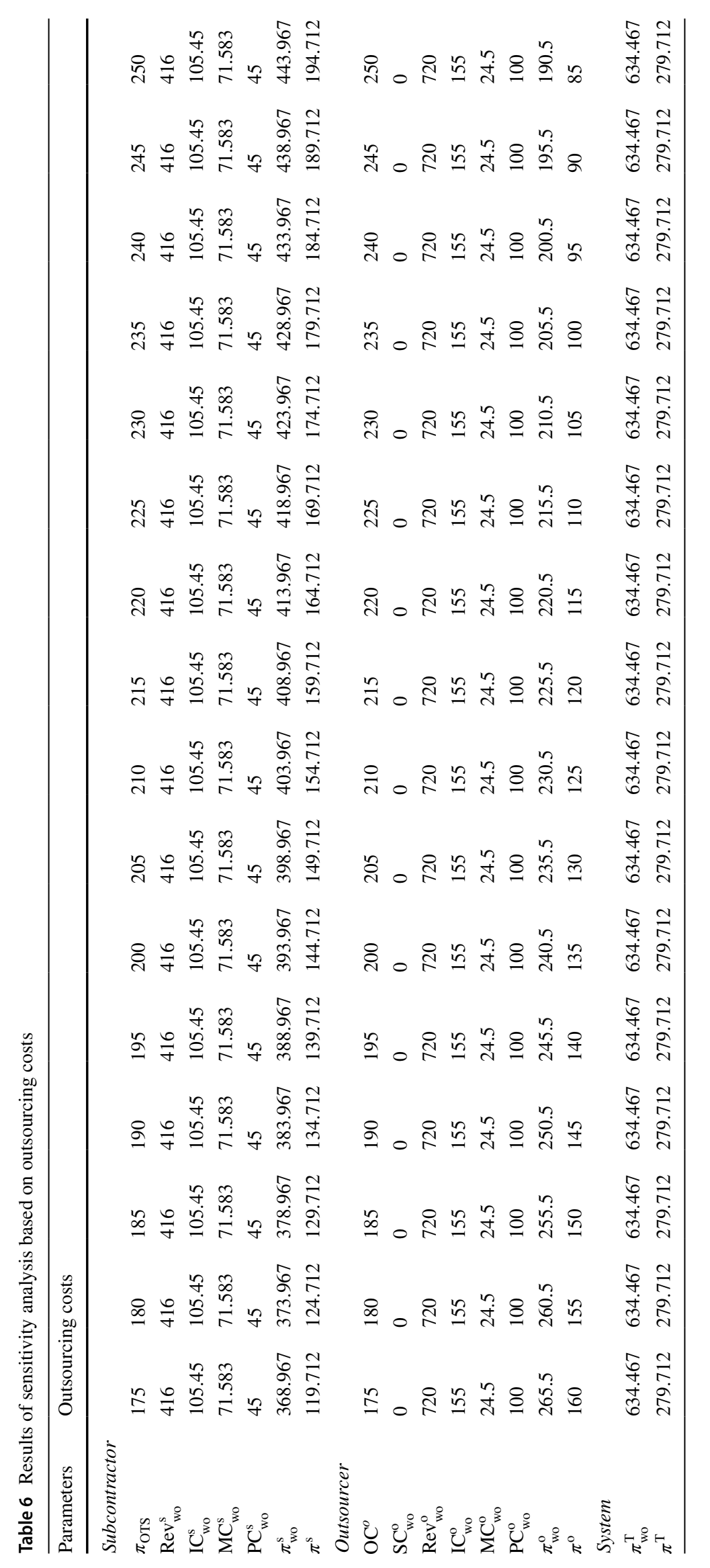




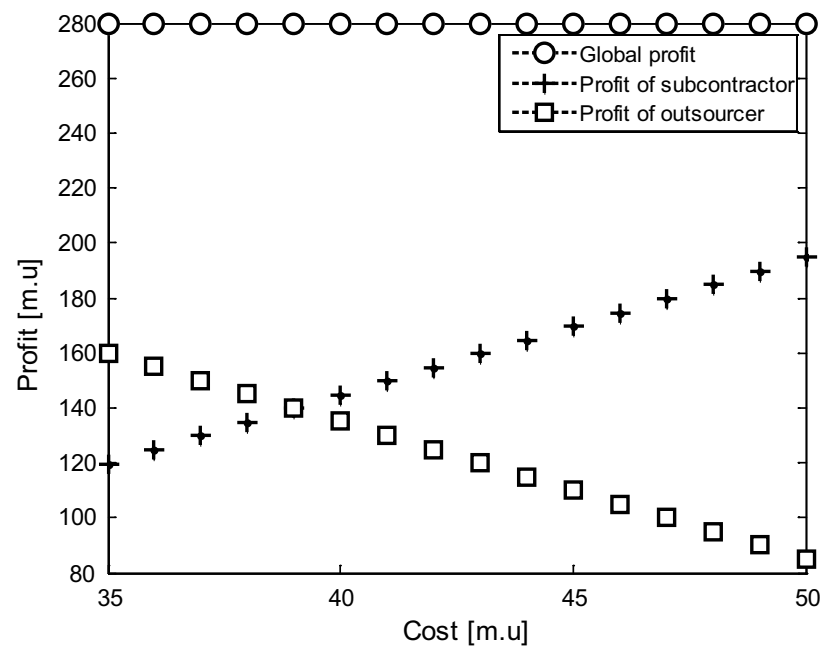

Fig. 4 Variation of the subcontractor, the outsourcer and the whole system profits according to outsourcing costs

approach. The approach is practical to be implemented as the results are obtained in a reasonable execution time.

It would be interesting as a forthcoming work to address the revenue sharing and compensation policies between the two parts. Furthermore, other maintenance policies can be considered, where such policies usually involve other more complicated issues not included in the current models.

Open Access This article is distributed under the terms of the Creative Commons Attribution 4.0 International License (http://creativeco mmons.org/licenses/by/4.0/), which permits unrestricted use, distribution, and reproduction in any medium, provided you give appropriate credit to the original author(s) and the source, provide a link to the Creative Commons license, and indicate if changes were made.

\section{References}

Abdel-Malek L, Kullpattaranirun T, Nanthavanij S (2005) A framework for comparing outsourcing strategies in multilayered supply chains. Int J Prod Econ 97(3):318-328

Adeyeri MK, Mpofu K (2017) Development of system decision support tools for behavioral trends monitoring of machinery maintenance in a competitive environment. J Ind Eng Int 13(2):249-264

Amelian S, Sajadi SM, Alinaghian M (2015) Optimal production and preventive maintenance rate in a failure-prone manufacturing system using discrete event simulation. Int J Ind Syst Eng 20(4):483-496

Arshinder K, Kanda A, Deshmukh SG (2011) A review on supply chain coordination: coordination mechanisms, managing uncertainty and research directions. In: Choi TM, Cheng TCE (eds) Supply chain coordination under uncertainty. Springer, Berlin, pp 39-82

Aydinliyim T, Vairaktarakis GL (2010) Coordination of outsourced operations to minimize weighted flow time and capacity booking costs. Manuf Serv Oper Manag 12(2):236-255

Cassady CR, Pohl EA, Murdock WP (2001) Selective maintenance modeling for industrial systems. J Qual Maint Eng 7(2):104-117

Dahane M, Rezg N (2011) Economic model of outsourcing for a subcontractor manufacturing system in a single subcontractor-multi-outsourcers relationship. In: Proceedings of IEEE conference on automation science and engineering, Trieste, Italy, 24-27 August 2011, pp 450-455

Dahane M, Dellagi S, Clementz C, Rezg N (2011) Development of joint maintenance and production strategies in a subcontracting environment. Int J Prod Res 49(23):1-25

Deavers KL (1997) Outsourcing: a corporate competitiveness strategy, not a search for low wages. J Lab Res 18(4):503-519

Dellagi S, Rezg N, Gharbi A (2010) Optimal maintenance/production policy for a manufacturing system subjected to random failure and calling upon several subcontractors. Int J Manag Sci Eng Manag 5(4):261-267

Dolgui A, Proth JM (2013) Outsourcing: definitions and analysis. Int J Prod Res 51(23-24):6769-6777

Dudek G, Stadtler H (2005) Negotiation-based collaborative planning between supply chains partners. Eur J Oper Res 163(3):668-687

Ezimadu PE, Nwozo CR (2017) Stochastic cooperative advertising in a manufacturer-retailer decentralized supply channel. J Ind Eng Int 13(1):1-12

Faghihinia E, Mollaverdi N (2012) Building a maintenance policy through a multi-criterion decision-making model. J Ind Eng Int. https://doi.org/10.1186/2251-712x-8-14

Geunes J, Chang B (2001) Operations research models for supply chain management and design. In: Floudas CA, Pardalos PM (eds) Encyclopedia of optimization, vol 4. Kluwer Academic Publishers, Dordrecht, pp 133-145

Gheidar Kheljani J, Ghodsypour SH, Brien CO (2009) Optimizing whole supply chain benefit versus buyer's benefit through supplier selection. Int J Prod Econ 121(2):482-493

Hajej Z, Dellagi S, Rezg N (2014) Joint optimization of maintenance and production policies with subcontracting and product returns. J Intell Manuf 25(3):589-602

Haoues M, Dahane M, Mouss NK, Rezg N (2011) Optimization of outsourcing activity under a win-win single outsourcer-single subcontractor relationship. In: Proceedings of the 41st international conference on computers \& industrial engineering, Los Angeles, CA USA, October 23-25, 2011, pp 343-348

Haoues M, Dahane M, Mouss NK, Rezg N (2012) Integrated maintenance problem in two-stage supply chain coordination with an outsourcing option. In: Proceedings of the 42 st international conference on computers \& industrial engineering, Cie \& Saiie, Cape Town, South Africa, 16-18 July, pp 937-951

Haoues M, Dahane M, Mouss NK (2016) Outsourcing optimization in two-echelon supply chain network under integrated productionmaintenance constraints. J Intell Manuf. https://doi.org/10.1007/ s10845-016-1273-3

Heydari J, Norouzinasab Y (2015) A two-level discount model for coordinating a decentralized supply chain considering stochastic price-sensitive demand. J Ind Eng Int 11(4):531-542

Jayaraman V, Pirkul H (2001) Planning and coordination of production and distribution facilities for multiples commodities. Eur J Oper Res 133(2):394-408

Khatab A, Dahane M, Ait-Kadi D (2014) Genetic algorithm for selective maintenance optimization of multi-mission oriented systems. In: Proceedings of the European safety and reliability conference, Wroclaw, Poland, September 14-18, 2014, pp 859-865

Kim B (2003) Dynamic outsourcing to contract manufacturers with different capabilities of reducing the supply cost. Int J Prod Econ 86(1):63-80

Krapp M, Kraus JB (2017) Coordination contracts for reverse supply chains: a state-of-the-art review. J Bus Econ. https://doi. org/10.1007/s11573-017-0887-z

Lee IS, Sung CS (2008) Minimizing due date related measures for a single machine scheduling problem with outsourcing allowed. Eur J Oper Res 186(3):931-952 
Lehoux N, D'Amours S, Langevin A (2010) A win-win collaboration approach for a two-echelon supply chain: a case study in the pulp and paper industry. Eur J Ind Eng 4(4):493-514

Nagali V, Hwang J, Sanghera D, Gaskins M, Pridgen M, Thurston T, Mackenroth P, Scholler P, Shoemaker G (2008) Procurement risk management (PRM) at Hewlett-Packard company. Interfaces 38(1):51-60

Özen U, Slikker M, Norde H (2009) A general framework for cooperation under uncertainty. Oper Res Lett 37(3):148-154

Rivera-Gómez H, Gharbi A, Kenné J-P, Montaño-Arango O, Hernandez-Gress ES (2016) Production control problem integrating overhaul and subcontracting strategies for a quality deteriorating manufacturing system. Int J Prod Econ 171(1):134-150

Rivera-Gómez H, Gharbi A, Kenné J-P, Montaño-Arango O, Hernandez-Gress ES (2018) Subcontracting strategies with production and maintenance policies for a manufacturing system subject to progressive deterioration. Int J Prod Econ 200(June 2018): $103-118$

Saharidis GKD, Kouikoglou VS, Dallery Y (2009) Centralized and decentralized control polices for a two-stage stochastic supply chain with subcontracting. Int J Prod Econ 117(1):117-126

Shahriari M, Shoja N, Ebrahimi Zade A, Barak S, Sharifi M (2016) JIT single machine scheduling problem with periodic preventive maintenance. J Ind Eng Int 12(3):299-310
Tambe PP, Kulkarni MS (2014) A novel approach for production scheduling of a high pressure die casting machine subjected to selective maintenance and a sampling procedure for quality control. Int J Syst Assur Eng Manag 5(3):407-426

Thomas DJ, Griffin PJ (1996) Coordinated supply chain management. Eur J Oper Res 94(1):1-15

Tsai W, Lai C (2007) Outsourcing or capacity expansions: application of activity-based costing model on joint products decisions. Comput Oper Res 34(12):3666-3681

Tsarouhas PH (2015) Performance evaluation of the croissant production line with reparable machines. J Ind Eng Int 11(1):101-110

Van Mieghem JA (1999) Coordinating investment, production, and subcontracting. Manag Sci 45(7):954-971

Zabihi F, Bafruei MK (2016) Supply chain coordination using revenue sharing contract with price discount and stochastic demand dependent on time and price. Int J Integr Supply Manag 10(2):132-150 